\title{
A rare presentation of metastatic prostate cancer, initially a suspect for urothelial cell carcinoma of the ureter: a case report
}

\author{
Ho Seok Chung ${ }^{1}$, Myung Soo Kim¹, Yang Hyun Cho', Eu Chang Hwang ${ }^{1 *}$ (D), Seung II Jung ${ }^{1}$, Taek Won Kang ${ }^{1}$, \\ Dong Deuk Kwon', Suk Hee Heo ${ }^{2}$ and Chan $\mathrm{Choi}^{3}$
}

\begin{abstract}
Background: The most common metastatic sites of prostate cancer are the lymph nodes and bone. Ureteral metastasis from prostate cancer is very unusual and only a few cases have been reported.

Case presentation: We describe a 76-year-old male with ureteral metastasis of prostate cancer along with a review of the literature. Initially, based on the diagnostic evaluation, urothelial cell carcinoma of the left distal ureter was suspected. Nephroureterectomy with bladder cuff excision was performed. The final pathologic diagnosis was prostate cancer metastatic to the ureter.

Conclusion: Although rare and the mechanistic link between prostate cancer and distant ureteral metastasis has not been clarified on a clinical basis, this would be included in the differential diagnosis of ureteral lesions in patients with a history of prostate cancer. It is important to recognize this unusual manifestation so that timely appropriate treatment can be initiated.
\end{abstract}

Keywords: Neoplasm metastasis, Prostate cancer, Ureter

\section{Background}

Prostate cancer, one of the most common malignancies in aging men, commonly spreads to lymph nodes and bone [1]. Ureteral metastasis from other primary cancers is very rare, and prostate cancer metastatic to the ureter is extremely rare, as only 45 cases have been reported worldwide in the last century [2,3]. Herein, we describe a patient with hydronephrosis secondary to a ureteral tumor caused by metastasis from prostate cancer.

\section{Case presentation}

A 76-year-old male visited the emergency room in June 2014 because of left flank pain. His past medical history was significant for advanced prostate cancer treated with androgen deprivation therapy (ADT). According to medical records, he first presented at our outpatient department with urinary obstructive symptoms and was

\footnotetext{
* Correspondence: urohwang@gmail.com

'Department of Urology, Chonnam National University Medical School, 42 Jebongro, Donggu, Gwangju 501-757, Republic of Korea

Full list of author information is available at the end of the article
}

diagnosed with prostate cancer (clinical stage T3bNOM0), with an initial serum prostate specific antigen (PSA) level of $80.69 \mathrm{ng} / \mathrm{ml} 2$ years earlier. At that time, we recommended ADT plus radiation for the treatment of the prostate cancer. However, the patient only received ADT. After 9 months of complete androgen blockade therapy, the PSA had decreased to $0.39 \mathrm{ng} / \mathrm{ml}$, but the patient was lost to follow-up and treatment.

When he again presented at the emergency room in June 2014, the PSA level was $6.75 \mathrm{ng} / \mathrm{ml}$. Abdominal computed tomography $(\mathrm{CT})$ revealed a left distal ureteral enhancing mass about $2.1 \mathrm{~cm}$ in length causing hydronephrosis, and no lymphadenopathy (Fig. 1). We initially performed left percutaneous nephrostomy for symptomatic hydronephrosis. Retrograde pyelography showed smooth, marginated filling defects in the left distal ureter (Fig. 2). Cytology showed no pathological results.

Because of suspected urothelial cell carcinoma of the left distal ureter, nephroureterectomy with bladder cuff excision was performed. Pathological examination revealed a lesion consisting of hyperchromatic cells around 

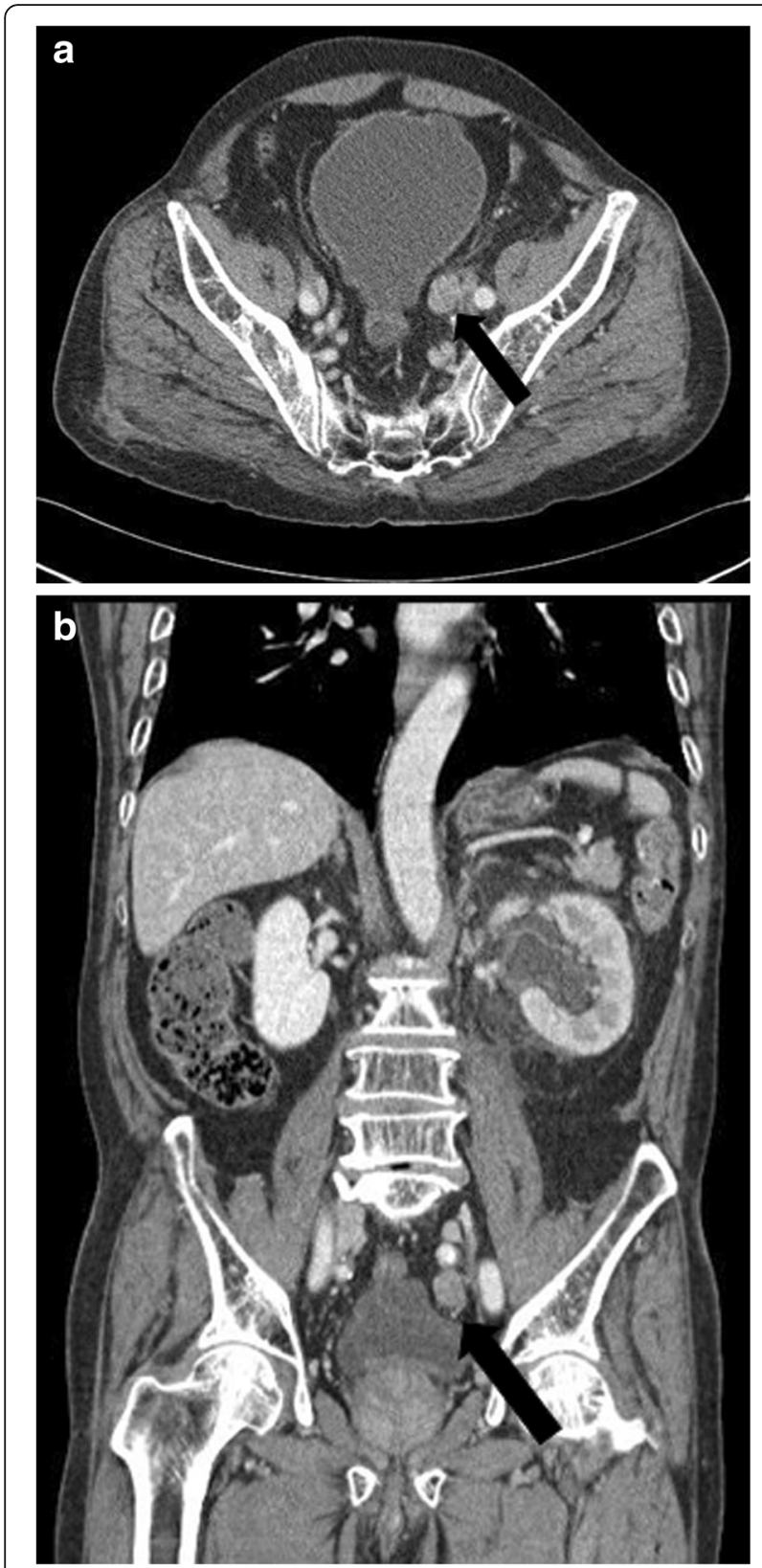

Fig. 1 Abdominal computed tomography showing a left ureteral mass with hydronephrosis. a axial view, b coronal view

the ureter (Fig. 3a). Immunohistochemical staining was strongly positive for prostate cancer markers, including p504S, PSA, and ERG, and negative for p63 (Fig. 3b-e). These findings confirmed a diagnosis of prostate carcinoma metastatic to the left ureter, with no evidence of urothelial cell carcinoma. The tumor invaded the adventitia and muscularis of the ureter, but the distal ureteral surgical margin was not involved by tumor cells.

After the operation, the patient was treated with complete androgen blockade therapy. However, at the 3month follow-up, the PSA level increased to $8.73 \mathrm{ng} / \mathrm{ml}$.

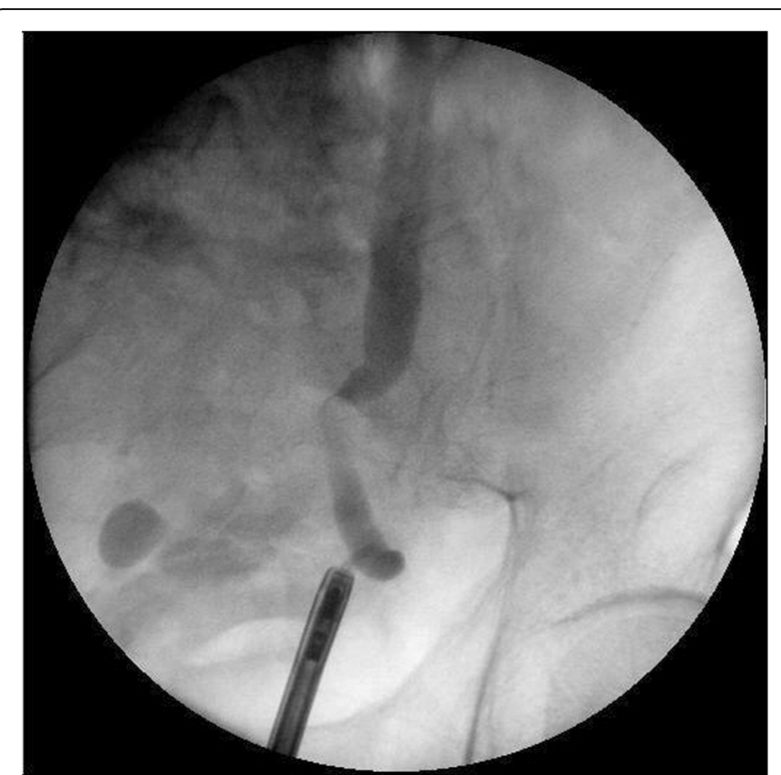

Fig. 2 Retrograde pyelography, showing smooth marginated filling defects in the left distal ureter

At the 1-year follow up, further progression with multiple bone metastases, metastatic lymphadenopathy, and right ureteral metastasis led to docetaxel chemotherapy following enzalutamide therapy, but terminating in death after the year.

\section{Discussion}

There is increasing discussion about the risk of development of a second primary cancer in prostate cancer patients [4]. Braisch et al. reported an increased risk of a subsequent primary cancer in the renal pelvis and ureter [5]. Ureteral lesions can also occur by metastasis from primary cancer. The most common malignancies that metastasize to the ureter are breast cancer, gastric cancer, and colorectal cancer [6]. However, ureteral metastasis from any type of primary cancer is unusual, because the ureters have segmental lymphatic circulation without continuation in the ureteral wall. Moreover, ureteral metastasis from prostate cancer is extremely rare, because there is no direct periureteral sheath drainage from the prostate [7]. The ureters can be affected by prostate cancer causing hydronephrosis through direct invasion of the tumor around the intravesical ureter. Prostate cancer may metastasize to the ureter through dissemination of malignant cells to the retroperitoneal lymph nodes near the ureter, via the periureteral lymphatic pathway [8].

A total of 38 cases of ureteral metastases from prostate cancer were described by Haddad in 1999 [2]. Since then, few cases have been reported $[3,6]$. In these cases, the most common symptom was flank pain caused by ureteral obstruction, as in our case. In addition, most ureteral metastases were treated by nephroureterectomy 


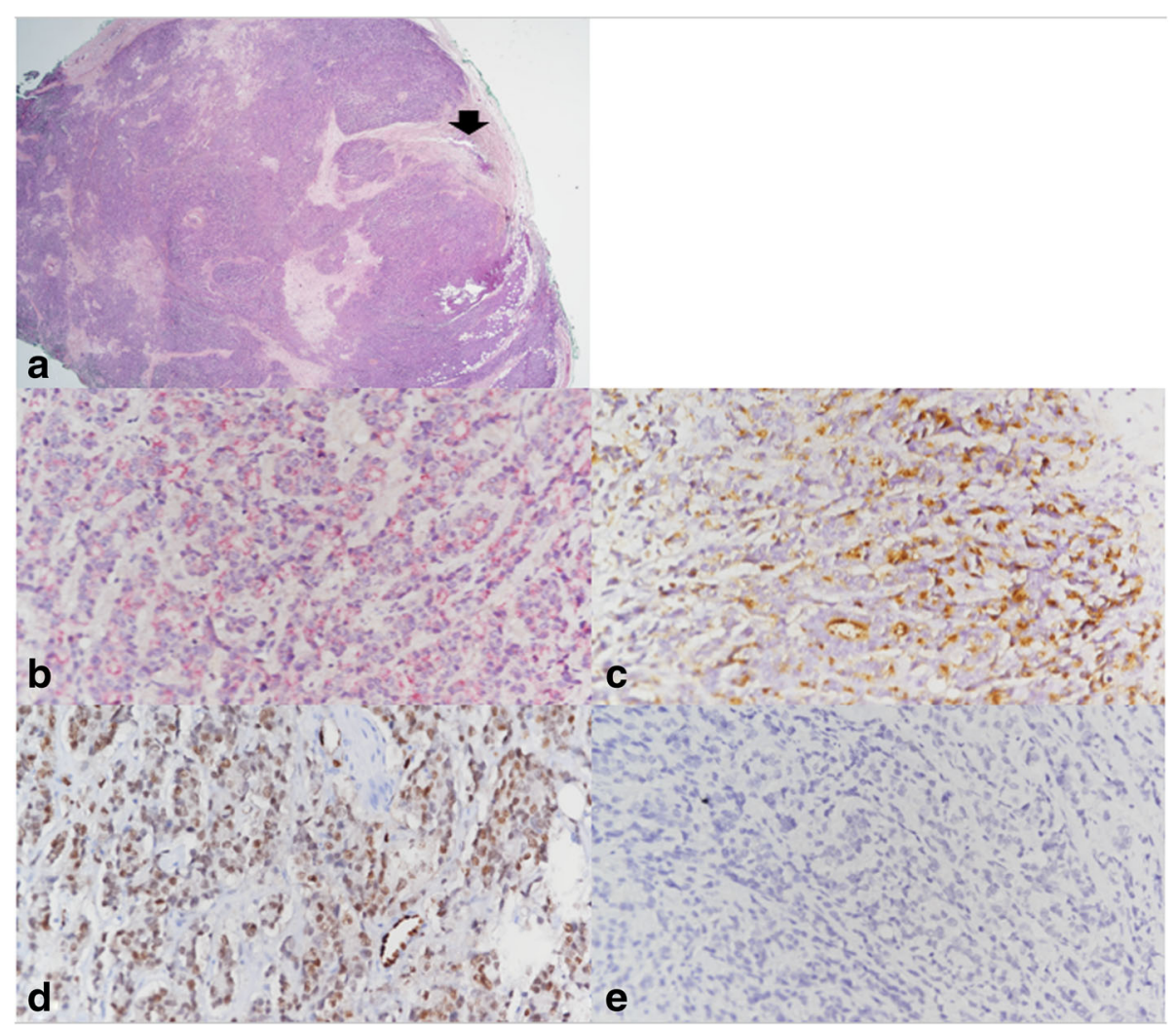

Fig. 3 Pathological features of the involved ureter. a Solid sheet of hyperchromatic cells are noted around the ureter. Arrow indicates ureter. (hematoxylin-eosin staining, $\times 10)(\mathbf{b}, \mathbf{c}, \mathbf{d}, \mathbf{e})$ The tumor cells were positive for p504S, prostate specific antigen (PSA), and ERG, and negative for p63 (immunohistochemical stain, $\times 200$ )

because of presumed upper urothelial carcinoma [3]. However, before surgery, diagnostic ureteroscopy and biopsy would be reasonable options for the differential diagnosis [9]. Because nephroureterectomy might have been avoided, and the ureteral mass could be regressed under antiandrogen treatment. For severe flank pain with hydronephrosis, immediate percutaneous nephrostomy or double J stent might be a good choice. Gross hematuria is rarely observed, possibly because most ureteral metastasis occurs beneath the mucosa and by invasion from surrounding tissues [6]. Most case series reported that primary prostate cancer metastatic to ureter had a Gleason score (GS) $\geq 7$ [3]. In our case, transrectal ultrasound (TRUS)-guided biopsy revealed prostate cancer with GS $9(4+5)$. It is possible that prostate cancer with a high GS is associated with the risk of ureteral metastasis [3].

\section{Conclusion}

Although rare, the urologist should consider metastatic disease in the differential diagnosis of ureteral lesions in a patient with a history of prostate cancer with a high GS. If ureteral metastasis is confirmed by ureteroscopic biopsy before definitive treatment such as nephroureterectomy, segmental ureterectomy and ureteroureterostomy could be applied in this condition for preservation of ipsilateral kidney. In addition, conservative treatment using nephrostomy or double J stenting may be helpful to relieve urinary obstructive symptoms.

\section{Abbreviation}

ADT: Androgen deprivation therapy; CT: Computed tomography; GS: Gleason score; PSA: Prostate specific antigen; TRUS: Transrectal ultrasound

\section{Acknowledgments \\ None.}

Funding

None.

Availability of data and materials

Not applicable. This is a case report.

Authors' contributions

HSC and ECH made contributions to conception and design, of acquisition of data. MSK, SIJ, TWK, and DDK have been involved in revising it critically. YHC, SHH, and CC analyzed and interpreted the patient data. All authors read and approved the final manuscript.

\section{Competing interests}

The authors declare that they have no competing interests. 


\section{Consent for publication}

Informed consent was obtained form legal guardian. The data do not contain any information that could identify the patient.

\section{Ethics approval and consent to participate}

Not applicable.

\section{Publisher's Note}

Springer Nature remains neutral with regard to jurisdictional claims in published maps and institutional affiliations.

\section{Author details}

'Department of Urology, Chonnam National University Medical School, 42 Jebongro, Donggu, Gwangju 501-757, Republic of Korea. ${ }^{2}$ Department of Radiology, Chonnam National University Medical School, Gwangju, Republic of Korea. ${ }^{3}$ Department of Pathology, Chonnam National University Medical School, Gwangju, Republic of Korea.

Received: 29 November 2016 Accepted: 12 May 2017

\section{Published online: 26 May 2017}

\section{References}

1. Gandaglia G, Abdollah F, Schiffmann J, Trudeau V, Shariat SF, Kim SP, Perrotte P, Montorsi F, Briganti A, Trinh QD, Karakiewicz PI, Sun M. Distribution of metastatic sites in patients with prostate cancer: a population-based analysis. Prostate. 2014:74:210-6.

2. Haddad FS. Metastases to the ureter. Review of the world literature, and three new case reports. J Med Liban. 1999;47:265-71.

3. Huang TB, Yan Y, Liu H, Che JP, Wang GC, Liu M, Zheng JH, Yao XD. Metastatic prostate adenocarcinoma posing as urothelial carcinoma of the right ureter: a case report and literature review. Case Rep Urol. 2014;2014:230852.

4. Van Hemelrijck M, Feller A, Garmo H, Valeri F, Korol D, Dehler S, Rohrmann S. Incidence of second malignancies for prostate cancer. PLoS One. 2014;9: e102596.

5. Braisch U, Meyer M, Radespiel-Tröger M. Risk of subsequent primary cancer among prostate cancer patients in Bavaria, Germany. Eur J Cancer Prev. 2012:21:552-9

6. Zhang D, Li H, Gan W. Hydronephrosis associated with ureteral metastasis of prostate cancer: a rare case report. Mol Clin Oncol. 2016;4:597-8.

7. Hulse CA, O'Neill TK. Adenocarcinoma of the prostate metastatic to the ureter with an associated ureteral stone. J Urol. 1989;142:1312-3.

8. Zhang T, Wang Q, Min J, Yu D, Xie D, Wang Y, Ding D, Chen L, Zou C, Zhang Z, Wang D. Metastasis to the proximal ureter from prostatic adenocarcinoma: a rare metastatic pattern. Can Urol Assoc J. 2014;8:E859-61.

9. Schneider S, Popp D, Denzinger S, Otto W. A rare location of metastasis from prostate cancer: hydronephrosis associated with ureteral metastasis. Adv Urol. 2012;2012:656023.

\section{Submit your next manuscript to BioMed Central and we will help you at every step:}

- We accept pre-submission inquiries

- Our selector tool helps you to find the most relevant journal

- We provide round the clock customer support

- Convenient online submission

- Thorough peer review

- Inclusion in PubMed and all major indexing services

- Maximum visibility for your research

Submit your manuscript at www.biomedcentral.com/submit
Biomed Central 